\title{
SESSION 1121
}

\section{Interconnected Learning in Construction Management Technology}

\author{
Amitabha Bandyopadhyay \\ Farmingdale State University of New York
}

\begin{abstract}
Construction is an integrative process and thus construction industry needs professionals who are capable of integrating knowledge from various areas. The construction educators must cultivate students' ability to bridge boundaries among courses taken from different disciplines. The Long Island Consortium for Interconnected Learning was a multi-year, multi-faceted initiative funded by the National Science Foundation (DUE9555401) to enhance instruction and learning in mathematically based disciplines. Interconnected learning in construction management was part of this initiative. The paper will focus on the construction management department's effort of this multidimensional project. It will detail how the department's faculty members organized and interacted among themselves as well as with faculty members from the other departments. Some of the specific activities that would be discussed in the paper are: restructuring of a surveying course to link it to mathematics courses, restructuring of a departmental computer programming and application course to make it relevant to other courses, restructuring of a statics course to link it to physics and mathematics courses, establishing peer tutoring and peer support groups for these courses, establishing active and cooperative learning environment, establishing critical thinking environment, establishing continuous group and self assessment environment.

Index Terms - Active-learning, Interconnected, Peer- assessment, Team

Introduction
\end{abstract}

A consortium of faculty at ten colleges and universities on Long Island, in conjunction with the State University of New York (SUNY) system, had designed a comprehensive, multi-faceted project to develop an environment for interconnected learning in mathematics courses and in mathematically based disciplines. The enhanced learning environment had three major components:

- Systemic change in instructional practices,

- Creation of new courses and curricular materials and,

- Development of human resources

The Long Island Consortium for Interconnected Learning began operation in March 1996. The Consortium had nine major activities:

- Changing modes of instruction

Proceedings of the 2005 American Society for Engineering Education Annual Conference \& Exposition Copyright

(C) 2005, American Society for Engineering Education 
- Connections between mathematics and other quantitative disciplines

\section{SESSION 1121}

- Use of educational technology

- New multi-disciplinary courses

- Unifying courses in different departments

- Calculus reform

- Pre-calculus reform

- Helping under-represented groups

- Teacher training

Headquartered at the State University of New York at Stony Brook, this project for systemic change involved an extensive organizational structure. It was engaging administrators as well as faculty and students in its agenda for change. It has a Faculty Development Award Program which has already nurtured a wide spectrum of grassroots innovative efforts by 70 faculty members.

The Long Island Consortium's premise was that, just as faculty undertake research on a wide variety of topics, so faculty efforts in instructional innovation will take on a wide variety of forms. The overarching objective of the project PIs was to make these diverse efforts "sum up" to create a self- sustaining institutional culture of coordination and improvement in quantitative instruction.

\section{Interconnected Learning in Construction Management}

Construction as an industry always drew knowledge and skills from diversified disciplines. Construction managers always had to integrate various crafts and materials to complete a project. Thus, integrated learning should naturally be done in construction management education. The department undertook two distinct efforts under the Long Island Consortium for Interconnected Learning project. They were Math Across Programming Surveying (MAPS) and Interconnected Construction (ICON) education. Although, both of these activities had some common elements, there were specific programmatic elements for each of the effort.

Math Across Programming and Surveying (MAPS)

Surveying is the art and science of determining the dimensions and contour of the earth's surface by measurements of distances, directions, and elevations. It also involves staking out the lines and grades needed for the construction of buildings, roads, dams, and other structures. In addition 


\section{SESSION 1121}

to these field measurements, surveying includes the computation of areas, volumes, and other quantities, as well as preparation of necessary maps and diagrams. The early development of surveying cannot be separated from the development of astronomy and mathematics. The term "geometry", in fact derived from Greek words meaning earth measurements.

More and more we had to deal with students at Farmingdale who lacks proper understanding of geometry and trigonometry. Although, most students take a pre-calculus course concurrently, a gap exist in application and relevance of mathematics skills in technology courses among majority of the students. A re-structuring of teaching and learning was done in our Surveying (CON103) course by adding applied topics in trigonometry and algebra, team learning, group assessment and active learning components. Similarly, the programming (CON164) was also restructured by using some of the similar activities. The course was re-named Introduction to Technology and Applied Programming

Interconnected Construction Education

As part of this effort a number inter related pedagogical activities were carried out. They were:

- Re-structuring statics (CON106) course to link with college physics (PHY 135) and prcalculus (MTH129)

- Establishing team learning environment

- Establishing active learning environment

- Establishing self assessment and individual assessment in group environment

- Establishing peer assessment

Learning in Team

A team is a group of people actively cooperating in an organized way to achieve a goal. . Learning in groups depends upon the synergy in a group. The assumption is the whole is more than the sum of the parts. Learning from each other and supplementing each other's strong attributes is the key in learning in groups. The relative effectiveness of different environments has shown the superiority of the learning in groups[1]. Students working in cooperative learning groups, relative to the other situations learn more. They also have more positive attitudes regarding the subject area. In a group environment students are more likely to acquire critical thinking skills, cognitive learning strategies and process skills that are essential in the work place [1]. As a team becomes involved in a lesson, the different information, perceptions, opinions, reasoning, theories, and conclusions of the members lead to disagreement. With constructive management such controversies promote questioning, an active search for more information, and finally a restructuring of knowledge. This cooperative process results in greater mastery of the subject matter, retention of materials learned and more frequent use of critical thinking and higher level reasoning [2].

Proceedings of the 2005 American Society for Engineering Education Annual Conference \& Exposition Copyright (C) 2005, American Society for Engineering Education 


\section{SESSION 1121}

\section{Active Learning for Construction Students}

Meta-cognition is a term used by cognitive psychologists to describe students' understanding of their own learning skills, performance, and habits [3]. Two broad aspects usually included are (1) awareness and knowledge of self-as-a-learner, and (2) self control and self-regulation of cognition. The ability of students to monitor their learning while it is in process to see if they really do understand the lecture or text. Examples of monitoring strategies are self-questioning, paraphrasing and summarizing. These monitoring activities help make students more active participants in their own learning and give them more control over their learning. The learner or the students are central focused. The students are confronted with tasks to complete, a time deadline, teammates, and instructor who wander around asking questions.

Most of the construction students are traditionally tactile learners. The hands-on approach in learning usually is the method of choice for the construction students. Engineering and technology courses always contained learning-by-doing components. However, to maximize the student's natural talents many construction courses are taught as "active learning in a group environment". The classes are typically divided into teams of three students. The teams are continuously involved in problem solving in the classroom, supplemented by short lectures. The students use various assessment tools and techniques as part of the learning process.

\section{Assessment: A Learning Component}

Assessment provides an environment for constant improvement. The essence of assessment is that it asks students to create something of meaning. A good assessment incorporates complex thinking and problem solving, addresses important disciplinary content, invokes authentic or real-world applications and uses tasks that are instructionally meaningful. Learning is not only a one-way transmission of information from teacher to students. Meaningful instruction engages students actively in their learning. Learning to be meaningful and effective it must have clear visions. Assessment is a key part of this vision. The good teachers constantly assess how their students are performing, gather evidence of the progress and problems, and adjust their instructional plans accordingly. The students in the construction courses continuously participate in group assessment, giving the instructor an opportunity to adjust the goals and instruction methodology. For example, in Construction Methods and Materials course, repeated references to lack of adequacy of the textbook promoted the instructor to provide additional handouts and increase frequency of short lectures and subsequently change the text in the following semester. So assessment in true sense is not only the evaluation of performance of the students, but the evaluation of the course as well as the instruction. Assessment is one component of the Teaching-Learning-Assessment-Improvement loop.

\section{Individual Assessment in Group Environment}

Individual accountability is a key factor in any learning and assessment environment. The ultimate goal of the program is to prepare each of the students for a professional construction 


\section{SESSION 1121}

position. Each student is monitored and assessed frequently. Individual accountability is promoted by keeping the teams small, by rotating the roles of the team members, and by giving short quizzes at the end of every session. To promote positive interdependence, individual quiz grades are averaged or summed to obtain a grade for the team that eventually affects every member of the team.

\section{Peer Assessment}

Peer evaluation and assessment is a part of the United States higher education for a long time. However, using peer evaluation or students are quite uncommon. At Farmingdale construction students are able to evaluate their peers in terms of their input for successful assignment completion. It is not only the peers' capability or their understanding of the subject matter but also their role of helping other students to learn. So, such assessment says more about validity of cooperative learning than just evaluating individuals.

\section{Self-Assessment in Group Environment}

In any course students are likely to learn more if they are capable of clearly articulating their goals and making connections between those and course goals and requirements [4] . Selfassessment is crucial to learning progress. Most students do have learning goals, although they may find it difficult to articulate them. The information about students' goals can be very useful to teachers in planning and continuous improvement.

\section{Conclusion}

One of the main objectives of the consortium was to change the culture of the traditional class room teaching by using various innovative and tested methods. Examining the re-structured courses, as they are taught now compared to the same courses taught five years ago, the change is definitely remarkable. It does not preclude them for further improvement in teaching and learning, and that is the essence of continuous improvement.

\section{Bibliography}

1. Johnson, D.W. and Johnson, R.T. (1989). "Cooperation and Competition: Theory and Research.” Interaction Book Co., Edina, Minnesota

2. Johnson, David W., Johnson, Roger T., and Smith, Karl A. (1991). "Active Learning: Cooperation in the College Classroom." Interaction Book Co., Edina, Minnesota.

3. Brown, A.L., Bransford, J.D., Ferrara, R.A., and Campione, J.C. (1983). "Learning, Remembering and Understanding". Handbook of Child Psychology Volume III: Cognitive development 4th ed., 77-166. John Wiley, New York. 


\section{SESSION 1121}

4. Cross, Patricia K. and Angelo, Thomas A. (1988). "Classroom Assessment Techniques A Handbook for Faculty." National Center for Research to Improve Postsecondary Teaching and Learning, the University of Michigan, Ann Arbor, Michigan.

\section{Biography}

AMITABHA BANDYOPADHYAY, Ph.D., P.E. is a distinguished service professor and chair of Architecture and Construction Management Department at State University of New York at Farmingdale. Dr. Bandyopadhyay is a member of ASEE, ASCE and many other regional professional and trade groups. His teaching and research interest is in the area of construction materials, construction engineering, and management. 